\title{
EL CAMPO SOCIAL Y ÉTICO DURANTE EL PERIODO DE CRECIMIENTO DE LAS EMPRESAS CON ESPÍRITU EMPRENDEDOR QUE "NACIERON GLOBALES"
}

\section{CRITICAL REVIEW OF THE SOCIAL AND ETHICAL FIELDS DURING THE PERIOD OF BUSINESS GROWTH OF COMPANIES WITH ENTREPRENEURIAL SPIRIT "WERE BORN-GLOBAL"}

\author{
Guido Romero Larco \\ Universidad Tecnológica Equinoccial \\ guido.romero@ute.edu.ec \\ Javier Benalcázar Ordóñez \\ Universidad Tecnológica Equinoccial \\ freddy.benalcazar@ute.edu.ec
}

RECIBIDO: 03 / 04 / 2017

APROBADO: 19 / 05 / 2017

\begin{abstract}
Resumen
Las empresas que "nacieron globalizadas" son la llave del crecimiento económico en diferentes países. Los autores investigaron el concepto social y asuntos éticos que tienen estas empresas emprendedoras durante los periodos de crecimiento de sus negocios. La falta de responsabilidad social ha empezado a marcar pérdidas económicas para las empresas, mientras que la permanente vigilancia de la sociedad premia con mayores ingresos a las empresas comprometidas con una adecuada responsabilidad social. Este documento entrega una revisión crítica y evaluación de cómo las compañías con base en su responsabilidad social y principios éticos han contribuido no solo con el desarrollo de la organización, sino también con el de la sociedad.
\end{abstract}

Palabras clave: Responsabilidad social; global; principios éticos; nacieron globales.

\begin{abstract}
:
Companies that "Born Globals", are the key to economic growth in different countries. The authors investigate the social concept and ethical issues that theses entrepreneurial companies have during the period of growth of their business. The lack of social responsibility has begun to mark economic losses for companies, while the permanent vigilance of the society rewards with greater income to the companies committed with an adequate social responsibility. This paper provides a critical review and assessment of how companies base on their social responsibility and ethical principles have contributed not only to the development of the organization but also to society.
\end{abstract}

Keyword: ethical; were born-global; business entrepreneurs; social

\section{Introducción}

El mundo se ha convertido en una aldea globalizada, y sin duda la globalización ha traído nuevos retos, oportunidades y riesgos para las empresas (Vasconcellos et al., 2011). Es importante explorar el concepto de las empresas que nacieron globales; además de conocer los cuatro tipos de empresas internacionales que influyen en la economía de los países. 
Las empresas se crean para ser lucrativas, conforme éstas van creciendo en el mercado buscan tener mayor rentabilidad y aumentar su riqueza; las empresas que nacieron globales no son la excepción ya que también buscan crecer en la industria y para ello deben tomar decisiones y estrategias. Las estrategias son importantes para las empresas ya que éstas enmarcan sus objetivos, decisiones y acciones (Pelham and Wilson 1995).

La globalización llama al libre mercado entre las naciones; pero a la vez se cuestiona si las empresas basan sus objetivos en su responsabilidad social y si sus estrategias tienen valores éticos que conlleven al bienestar de la sociedad. Las empresas que nacieron globales buscan generar más lucro para sus arcas, pero ¿Sus acciones estarán más enmarcadas al enriquecimiento de sus accionistas o al bienestar de la comunidad?

\section{Nacido Global}

La continua y creciente globalización de los mercados está llevando a las empresas a buscar su internacionalización con el objetivo de crecer y aumentar su rentabilidad. La internacionalización según Welch\&Luostarinen (1999) es cuando las empresas empiezan a operar en el exterior e ingresan a mercados extranjeros. Esto implica un manejo más complejo en la cadena de abastecimiento (suministros).

Mendoza y Vives (2008) en el IV Informe anual del OEME (2015) señalan que una vez que las empresas se han logrado posicionar en su mercado local, pueden empezar su proceso de internacionalización, mismo tiene dos etapas:

- Expansión Internacional (Coloca filiales en otros mercados / países)

- Adaptación de su estrategia con base a la cultura de cada país.

Figura 1. PROCESO DE INTERNACIONALIZACION

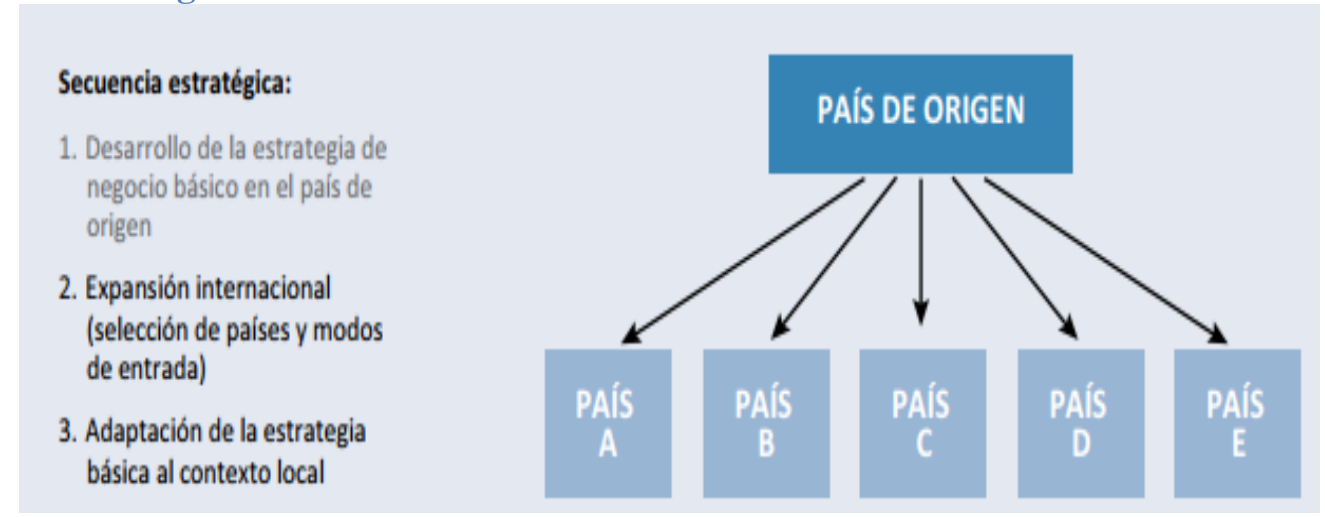

Fuente: Mendoza y Vives (2008) en el IV Informe Anual del OEME (2015)

Por otro lado, Johanson y Vahlne (1990) indican que las empresas tienen 5 pasos para la internacionalización:

1. Desarrollo en su mercado local

2. Realizan exportaciones irregulares

3. Utilizan agentes independientes

4. Colocan filiales comerciales en otros mercados / países

5. Establecen filiales productivas

Utilizando la historia de TOYOTA, los autores desarrollan la siguiente cronología en la cual se puede observar que el periodo de internacionalización de Toyota le tomo más de 20 años: 
Cuadro 1. PROCESO DE INTERNACIONALIZACION DE TOYOTA

\begin{tabular}{|c|c|c|}
\hline \multicolumn{2}{|r|}{ ETAPAS } & CRONOLOGÍA \\
\hline $\begin{array}{c}\text { Etapa } \\
1\end{array}$ & $\begin{array}{l}\text { Desarrollo en su } \\
\text { mercado local }\end{array}$ & $\begin{array}{l}\text { 1937: Nace Toyota } \\
\text { 1947: Toyota lanzó su primer automóvil pequeño (Modelo SA) } \\
\text { 1950: Se funda Toyota Motor Sales }\end{array}$ \\
\hline $\begin{array}{c}\text { Etapa } \\
2\end{array}$ & $\begin{array}{l}\text { Exportaciones } \\
\text { irregulares }\end{array}$ & 1953: 5 unidades Land Cruiser fueron exportados al Salvador \\
\hline $\begin{array}{c}\text { Etapa } \\
3\end{array}$ & $\begin{array}{l}\text { Utilizan Agentes } \\
\text { independientes }\end{array}$ & $\begin{array}{l}\text { 1957: El Toyota Crown se convirtió en el primer automóvil japonés } \\
\text { exportado a los Estados Unidos }\end{array}$ \\
\hline $\begin{array}{c}\text { Etapa } \\
4\end{array}$ & $\begin{array}{c}\text { Colocación de } \\
\text { filiales } \\
\text { comerciales en } \\
\text { otros mercados / } \\
\text { países }\end{array}$ & $\begin{array}{l}\text { 1957: Se establece la división de Toyota en EEUU: Toyota Motor } \\
\text { Sales Inc y Toyota en Brasil: Toyota do Brasil }\end{array}$ \\
\hline $\begin{array}{l}\text { Etapa } \\
5\end{array}$ & $\begin{array}{l}\text { Establecen } \\
\text { filiales } \\
\text { productivas }\end{array}$ & $\begin{array}{l}\text { 1959: Producción de automóviles fuera de Japón en Brasil. Continuó } \\
\text { con una creciente red de plantas en todo el mundo } \\
\text { 1960: Se establece en Tailandia (Instalación de investigación y } \\
\text { desarrollo) } \\
\text { 1970: La expansión continua en otros países } \\
\text { 1982: Crea una base en UK debido a la popularidad de la marca en el } \\
\text { mercado inglés } \\
\text { Actualmente, Toyota tiene fábricas en todo el mundo, manufactura o } \\
\text { ensambla sus vehículos en países como USA, Ecuador, Australia, } \\
\text { Canadá, Indonesia, Polonia, Sudáfrica, México, Pakistán entre otros }\end{array}$ \\
\hline
\end{tabular}

\section{Gráfico 1. PROCESO DE INTERNACIONALIZACION DE TOYOTA}

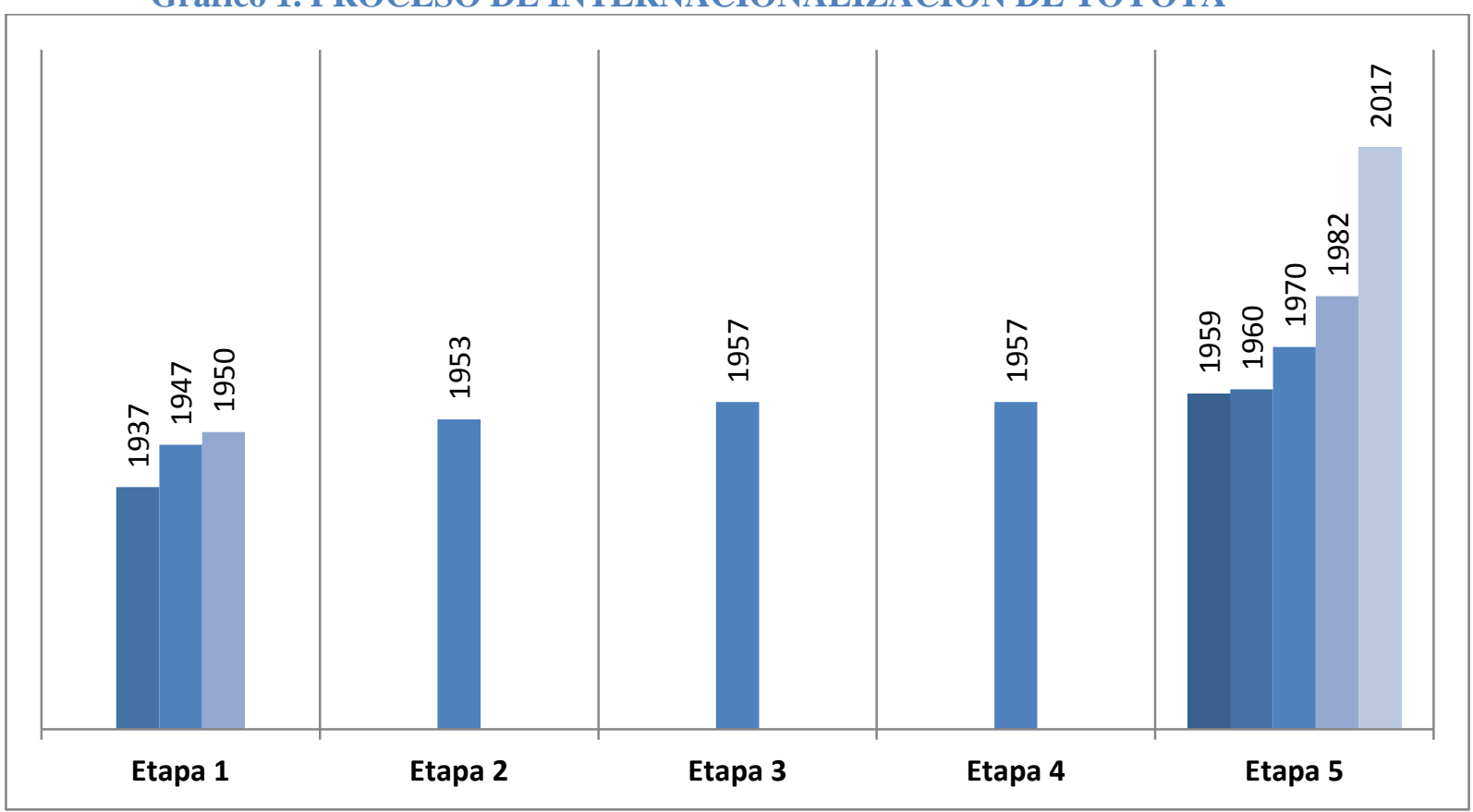

Fuente: http://es.calameo.com

Elaboración de los autores (2017), basada en la información fuente 
El siglo XXI ha creado un nuevo tipo de organizaciones que pueden describirse como organizaciones "nacidas globales'. De acuerdo con (McKinsey\&Company, 1993) "ellos poseían clientes, no productos. Para entender y satisfacer las necesidades de un grupo particular de clientes mejor que nadie en el mundo, decidieron crear un mercado donde prácticamente no tienen competidores. Las empresas que nacieron globales son flexibles y se mueven rápido". Estas organizaciones no necesitan entrar en el mercado paso a paso (en promedio 27 años) como las compañías internacionales (Johnson, 2005).

Son negocios de tamaños pequeños o medianos (aproximadamente 500 personas) y logran nichos de mercados globales usando productos innovadores. Estas empresas crean fuertes redes y cooperaciones (negocios asociados, empresas de apoyo, Internet). Sin duda estas organizaciones tienen un activo único e intangible (McKinsey\&Company, 1993) (Persinger, 2007).

Según (McDougall\&Ovaitt, 2005), las organizaciones globales nacientes son empresas que inician sus operaciones internacionalmente. Las mismas han venido creciendo desde 1980. Estas organizaciones son capaces de tener una enorme dispersión geográfica. Necesitan manejar operaciones por encima de la distancia. Generalmente tienen recursos limitados y experiencias internacionales. Ellos han operado desde el desarrollo de una nueva tecnología de fabricación, transportación, información y un bajo costo de comunicación. Crecieron bajo la reducción de barreras para el comercio de los negocios. Por ejemplo Facebook (Red Social), Youtube, Google, y Cochlear Ltd.

Como (Mika Gabrielsson, 2004) (McKinsey\&Company, 1993), señalan que los negocios nacidos globales son organizaciones que tienen un crecimiento dentro de 15 años máximo. La mayoría de las compañías se convierten en globales dentro de dos o tres años. Esas compañías tienen más de la mitad de ventas afuera de su continente. Son importantes porque son altamente competitivas frente a las grandes compañías establecidas. Tienen grandes beneficios y ayudan al rápido crecimiento de la economía global.

Según (Brenes Leiva \& León Darder, 2008) las organizaciones globales nacientes ingresan a los nuevos mercados saltándose algunas de las etapas del proceso de internacionalización, las mismas que son graduales y lentas para las empresas tradicionales.

Basándonos en el crecimiento de Amazon, los autores desarrollan la siguiente cronología en la cual se puede observar que el periodo de internacionalización de Amazon empezó desde el día uno.

\section{Cuadro 2. PROCESO DE INTERNACIONALIZACION DE AMAZON}

\section{CRONOLOGÍA}

1994: Nace Amazon. A los dos meses de su creación ya tenía presencia en 50 estados de Estados Unidos y en 45 países de todo el mundo con ventas de más de $\$ 20000$ por semana

1996: Posee un sitio para comprar online. Alcanza 180000 cuentas de clientes con ingresos de $\$ 15.7$ millones

1997: Necesita fondos privados por lo que se convierte en una Empresa Pública. Alcanza 1000000 cuentas de clientes. Obtiene ingresos de \$ 148 millones

1998: Alcanza ingresos de $\$ 610$ millones

1999: Tiene más de 350000 sitios para comprar online con amplia gama de ventas: video juegos, aparatos electrónicos, software, items para mejorar la casa, juguetes entre otros artículos

2002: La compañía lanza Amazon Web Services (AWS)

2007: Lanza Kindle e-readers (venta de libros electrónicos)

2009: Compra shoe seller Zappos, una tienda en línea en $\$ 847$ millones 
2011: Introduce al mercado su tableta (amazon-kindle-fire)

2012: Lanza Amazon Game Studios. Amazon tuvo ventas de $\$ 775$ millones

2013: Cuenta con 77 centros logísticos en todo el mundo

2017: Compra la cadena de supermercados Whole Foods Market, Inc. Posee presencia directa en Estados Unidos, Inglaterra, Alemania, Francia, Italia, España, Japón, Canadá y China; sin embargo, puede servir a los clientes en la mayoría de los países del mundo.

\section{Gráfico 2. PROCESO DE INTERNACIONALIZACION DE AMAZON}

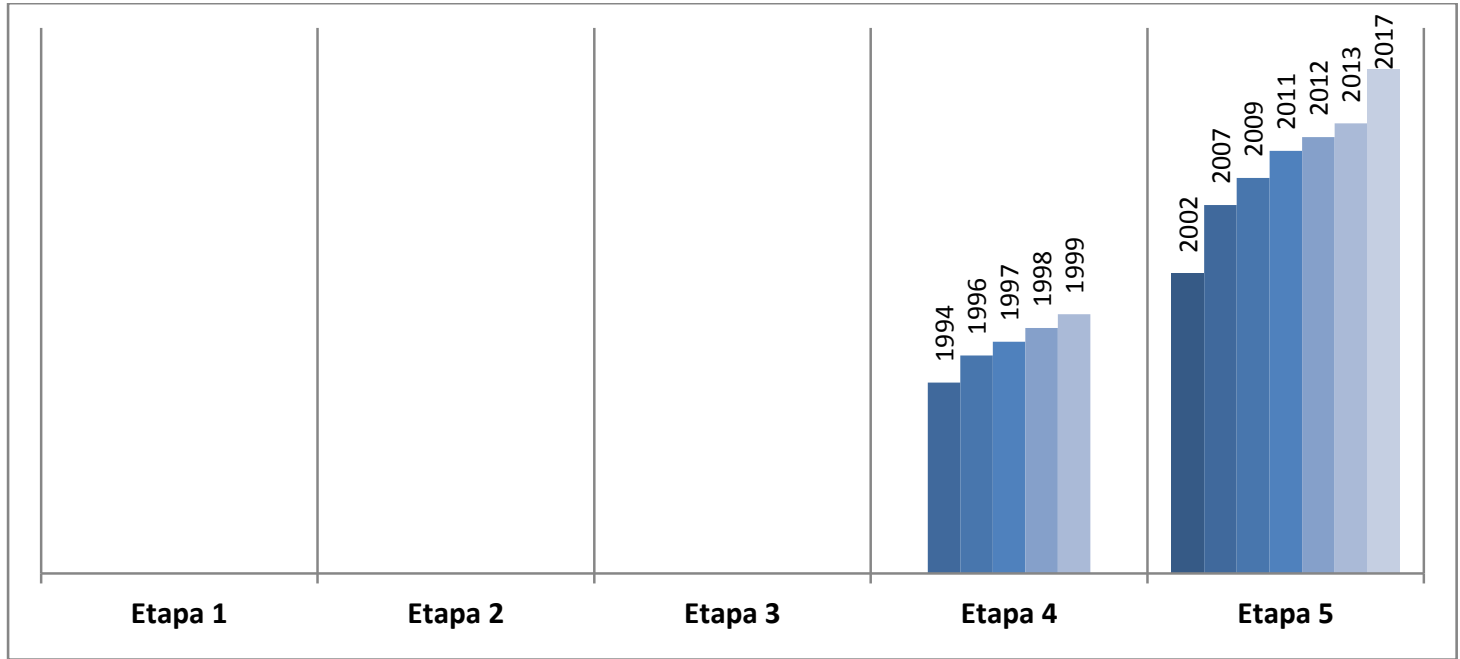

Fuente: (Hall, 2017), (Amazon.es, 2017), (Novoa, 2013),

Elaboración de los autores (2017), basada en la información fuente

\section{Gráfico 3. DIFERENCIA DEL PROCESO DE INTERNACIONALIZACION: TOYOTA} VS. AMAZON

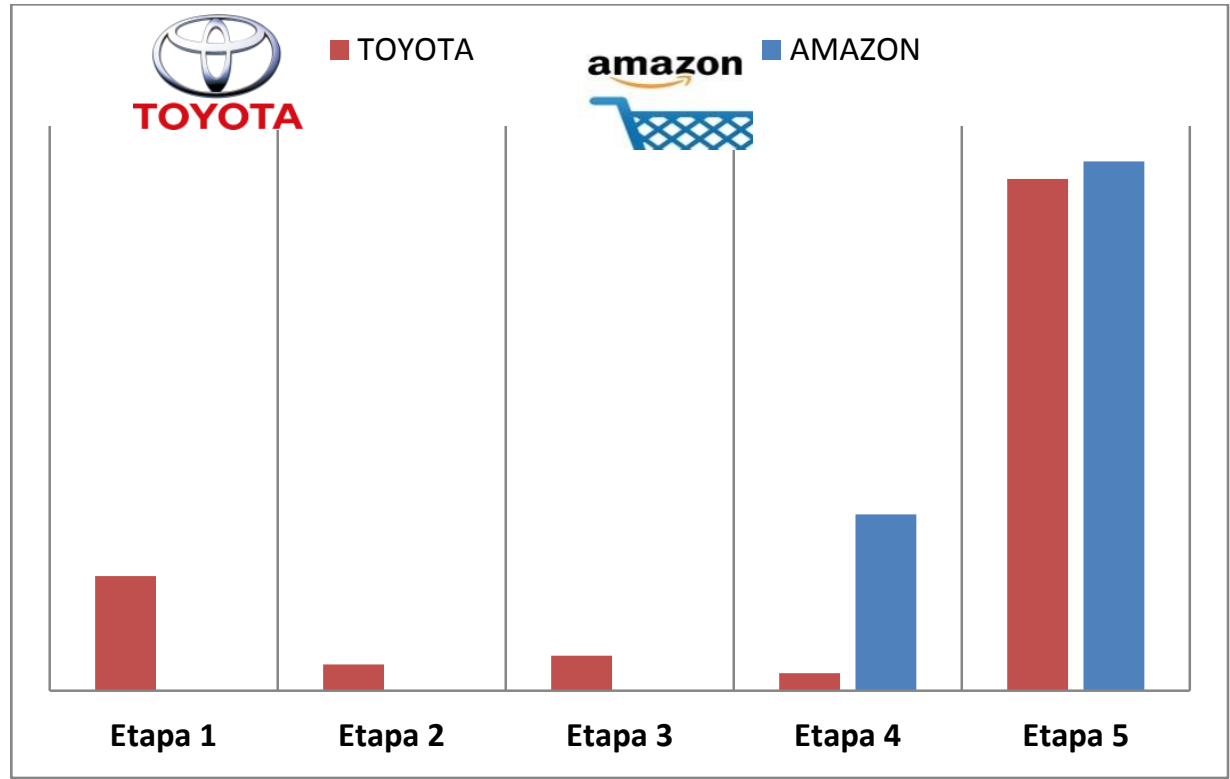

Fuente: (Hall, 2017), (Amazon.es, 2017), (Novoa, 2013)

Elaboración de los autores (2017), basada en la información fuente 
Además (Mika Gabrielsson, 2004), señaló que una organización es capaz de convertirse en "nacida global" cuando esta es capaz de ofrecer alta tecnología como componentes electrónicos e instrumentos médicos, altos servicios como consultoría, altos diseños o productos innovadores, altos conocimientos sobre mercados internacionales y finalmente altos sistemas como por ejemplo sistemas de producción, sistemas de control de seguridad. De acuerdo con un artículo de Matt Warman publicado en The Daily Telegraph (17-06-2010) Google "es capaz de procesar cientos de miles de páginas al mismo tiempo, y añadir nueva información a su índice de cientos de miles de gigabytes por día"

De acuerdo con (Benjamin M. Oviatt, 2005), nosotros tenemos 4 tipos de empresas internacionales. Estas son: Export/import Start-Ups (Exportadoras/Importadoras), Multinacional Trader (Comerciantes Multinacionales), Geographycal Focuced Start -Ups (Enfocadas Geográficamente) y Global Start-Ups (Empresas globales).

Estas empresas son la base de la economía de muchos países, por lo que la investigación muestra las diferencias que existen entre estas:

Export/import Start-Ups opera en algunos países mientras que Multinacional Trader opera en muchos países.

Export/Import and Multinacional Trader operan con logística primaria mientras que Geographycal Focuced Start -Ups operan importando recursos del extranjero (materia prima, productos semi-facturados, conocimiento). Estas organizaciones logran cumplir con una necesidad específica de una región determinada.

Multinacional Trader operan en muchos países mientras que Geographycal Focuced Start -Ups opera en regiones específicas.

Export/import Start-Ups y Geographycal Focuced Start -Ups operan en algunos países mientras Global Start-Ups operan en muchos países.

Es importante señalar que Global Start-Ups logra la mayor ventaja competitiva usando recursos únicos (principales competencias), y una efectiva coordinación de sus actividades a través del mundo.

\section{Crecimiento del negocio}

En la fase del crecimiento del negocio una organización maximiza el lucro e incrementa sus ventas (Paul Burns, 1996)

En esta fase una organización tiene éxito, pero la pregunta es ¿cómo mantener ese éxito?

Un negocio nacido global durante "el ciclo de vida del negocio" debe determinar ¿Qué? ¿Dónde? y ¿Cómo? quiere lograr sus objetivos en el mercado. Como (Paul Burns, 1996) argumenta: "Los negocios de rápido crecimiento tienen una estrategia de desarrollo (plan de negocios), introduciendo nuevos productos, desarrollando nuevos mercados y manteniendo buenas conexiones con los bancos"

Un negocio a nivel global necesita tener una clara imagen sobre su ambiente interno y externo. De acuerdo con (Burns, 2001) las organizaciones tienen que entender porque han sido prosperas.

Para ello una organización necesita hacer los siguientes análisis:

- Análisis FODA: Es una herramienta que permite primero, un análisis interno sobre fortalezas y debilidades y segundo un análisis externo sobre las oportunidades y amenazas que una organización enfrenta (Paul Burns, 1996).

- Análisis PESTEL: Muestra el micro ambiente de una organización, factores políticos, económicos, sociológicos y aspectos tecnológicos. (Adrian Palmer, 2002)

- Análisis de las Cinco Fuerzas de Porter: Permite a una organización ganar más entendimiento sobre la industria donde se desarrolla y así logra identificar: obstáculos para entrar, el poder del proveedor y los compradores, amenazas de los sustitutos y de 
los competitivos rivales que enfrenta en su industria (Porter, 1985) en (Paul Burns, 1996). ${ }^{1}$

Google por ejemplo respondió con el rápido crecimiento de Facebook y Twitter. Esta empresa mejoró e incorporó más datos que hizo que su servicio sea más eficiente. Toda esta mejora fue posible por la nueva tecnología (Warman, 2010).

En lo que respecta a la cultura organizacional, en la que se desenvuelven las empresas esta será primordial para logar éxito y tomar decisiones. (Robbins, 2009) señaló que la organización crea su cultura de acuerdo a sus normas, valores (responsabilidad social, innovación, etc.) mitos y estructura. Las personas se comportan de acuerdo a la cultura de la organización.

La cultura organizacional es determinada por la cultura nacional, industrial y la cultura de los negocios. Las organizaciones nacidas globales necesitan tener un exitoso entendimiento con la cultura de cada país para alcanzar sus objetivos. Las empresas nacidas globales tienen una visión global de su cultura. Estas organizaciones tienen una cultura geocéntrica (Persinger, 2007)

Por ejemplo: Moment Corporation of Montain View, California fue creada en 1980. Desde sus principios su filosofía fue ser global. (Benjamin M. Oviatt, 2005) señalan que "el diseño del software fue conducido por EE.UU y el hardware por Alemania, la fabricación en la Costa del Pacifico y los fondos vinieron desde Taiwan Singapur, Europa y Estados Unidos.

De acuerdo con (Mika Gabrielsson, 2004) 'estas compañías no necesariamente tienen tiempo para proceder de acuerdo al patrón convencional "teoría de la etapa".

En otras palabras las empresas que "nacieron globales" no pueden crecer gradualmente, éstas necesitan tomar una oportunidad en el mercado tan pronto como sea posible, puesto que deben tener una capital de trabajo para empezar y mantener sus operaciones de globalización.

Las empresas nacidas globales, para financiar sus recursos y cumplir con sus necesidades de expansión global (crecimiento), poseen las siguientes características (Mika Gabrielsson, 2004):

- Falta de flujo de caja, pero las compañías tiene un alto desarrollo en los costos

- Las demandas para financiar sus operaciones no son graduales, y

- Estas compañías necesitan suficiente capital de trabajo para lograr un alto crecimiento.

(McKinsey\&Company, 1993) argumenta que algunas empresas nacidas globales tuvieron los siguientes pasos de crecimiento:

- Producto o procesos desarrollados.

- Ventas solo en mercados locales

- Empezar a exportar (promedio: 2 años)

- Crear una posición internacional

- Enfrentar una transición de manejo de la organización

- Alcanzar un nicho (Los nichos de mercado que nacieron gracias a las empresas nacidas globales se mantienen por la innovación permanente)

Una vez desarrollado el crecimiento de las empresas que "nacieron globalizadas" podemos decir que todo tipo de organización quiere maximizar sus ganancias.

La pregunta que nace es ¿los dueños buscan maximizar sus ganancias, incluso por encima de sus responsabilidad social y valores éticos?

\section{Cuestiones sociales y éticas}

\footnotetext{
${ }^{1}$ Paul Burns, J. D. (1996). Small Business and Entrepreneurship. Southern Europ: Macmillan.
} 
De acuerdo con (Siropolis, 1998) la responsabilidad social es "el círculo de importancia y preocupación que un negocio tiene por el bienestar de la sociedad".

En otras palabras una organización es responsable de las necesidades de la sociedad. La responsabilidad social involucra la igualdad de responsabilidades, derechos sociales, salud, seguridad, salario apropiado, bienestar, justicia pero también incluye una política ambiental (Siropolis, 1998).

Algunos gobiernos como el Ecuador tienen establecido un salario mínimo vital; sin embargo, ¿todos los negocios realmente lo pagan?

(Paul W. Dobson, 2004) argumenta que una organización no tiene solo la responsabilidad con los accionistas y empleados. Tiene una responsabilidad con su comunidad y sociedad. Las organizaciones tienen una responsabilidad de ayudar al crecimiento económico del país.

(McKinsey\&Company, 1993) señalan que las organizaciones empresariales nacidas globales son responsables de incrementar el trabajo y juegan un importante rol en el desarrollo económico.

Adicionalmente, debemos decir que una organización necesita tener ética como parte de su responsabilidad corporativa y aseguramiento de toma de decisiones basadas en un juicio moral (Paul W. Dobson, 2004)

Por el contrario (Friedman, 1970) y (Bakan, 2005) en (Matten, 2010) señalan que: no están de acuerdo con la responsabilidad social de las organizaciones, para lo cual Friendman basa su teoría en lo siguiente:

- Las organizaciones no son seres humanos, ellas no tienen responsabilidad moral por sus acciones.

- Los gerentes deben cumplir los intereses de los accionistas (crear ganancias)

- El gobierno debe velar por el interés de su población. Los estados tiene el poder y la responsabilidad de crear leyes para proteger y mejorar el estilo de vida de las personas y asegurar que las organizaciones se manejen en un margen de responsabilidad social y normas éticas.

Por el contrario, autores como (Wendell L. French, 1999) en (Matten, 2010) argumentan que las organizaciones son creadas dentro del dominio de creencias y valores, esto crea su cultura organizacional. La cultura organizacional tiene una influencia de un comportamiento y toma de decisiones éticas individuales. Por lo tanto, una corporación tiene una responsabilidad legal por sus acciones.

La investigación indica, que las organizaciones son conscientes del sentido de la responsabilidad social, ellas pueden mantener las costumbres y evitar boicots. Las organizaciones quieren evitar que quienes compran sus productos/servicios perciban que son organizaciones egoístas.

Cuando los consumidores perciben que las empresas tienen responsabilidad social, éstas añaden un valor extra a la marca y/o servicio. Las corporaciones pueden mejorar su rendimiento, cuando los empleados perciben que la organización es socialmente responsable (Matten, 2010). Además, las actividades de una corporación deben tener alta relación con la moralidad, debido a que la falta de misma crea problemas sociales. Las actividades de una organización tienen un impacto social (positivo, negativo o neutral). Las redes sociales son un ejemplo. Morduchowicz et al (2010) señala que son "comunidades virtuales", es decir, las personas comparten intereses comunes a través de la red y uso de un computador. Entre las más conocidas tenemos Facebook, Twitter, WhatsApp, Instagram. 
En Facebook por ejemplo, los usuarios bajan fotos, comentan su estado, ubicación, donde estudian o trabajan, agregan nuevos contactos en la red entregando información privada y en algunos casos a personas desconocidas. La gente empieza a tener relaciones "parasociales" con personajes ficticios. Las personas gastan mucho tiempo en frente de un computador en vez de hacer actividades reales. Nosotros vivimos ahora en un mundo de intimidad digital. La pregunta es ¿Esta bien hacer dinero de nuestra privacidad? Facebook tuvo un ingreso neto en la primera parte del trimestre del 2017 de 3313.73 millones de dólares. (www.elmundo.es, 2017). Finalmente, hoy en día las organizaciones han ganado poder, y tienen un impacto masivo en el crecimiento del bienestar de un país. Los gobiernos han fallado en muchas maneras. La globalización ha delegado un rol político a las corporaciones.

Por ejemplo, la empresa Cochlear Ltda. desarrolla dispositivos auditivos implantables que ayudan a personas con discapacidad auditiva. La inspiración del fundador fue ayudar a su padre sordo.

Ahora, esta corporación controla aproximadamente un $70 \%$ del mercado con un crecimiento del $20 \%$ anual. En el 2004, tuvo ventas de \$310.24 millones de dólares. Esta compañía tiene grandes ganancias pero a la vez mejora la vida de las personas sordas. Lee Howlett indica que sus "clientes", aseguran que la mejor parte de su implante es la capacidad de hablar con su familia por el teléfono y oír el latido del corazón de su bebé por nacer".

(Matten, 2010) argumenta "la ética de negocios es estudiada por la situación de las actividades y decisión de los negocios donde cuestiones correctas o incorrectas son dirigidas"

Según (Matten, 2010) cada actividad de un negocio necesita involucrar principios y valores para tomar decisiones.

Collins \& Watson (1994) en (Matten, 2010) señaló "las actividades de negocios requieren mantenimientos de los básicos estándares éticos, como la honestidad, la integridad y cooperación. Esto no será posible si una corporación de directores siempre mienten, si los compradores y vendedores no confían entre sí, o si los empleados se rehúsan en ayudarse entre ellos.

(WetFeet, 2008) en (Matten, 2010) indica que aproximadamente 505 de los negocios ejecutivos piensan que las organizaciones hacen una buena contribución a la sociedad, mientras un $25 \%$ piensa que es negativa. Entonces, ¿cuál es el nivel de los negocios éticos?

Los negocios "nacidos globales" se enfrentan y se acoplan a diferentes culturas. Por lo tanto hay veces que ellos viven las contradictorias demandas éticas.

Google por ejemplo tiene más de 150 dominios y esto funciona en más de 110 lenguajes. Como (Matten, 2010) argumenta que los valores éticos y hábitos son diferentes en todos los países.

En China se piensa que no es un comportamiento ético despedir empleados. Mientras que en Europa en tiempos de recesión económica se piensa que es correcto el despedido de las personas para mantener ganancias y sobrevivir en situaciones de recesión y/o problemas económicos. Como podemos ver, las culturas crean diferentes perspectivas y esto determina su comportamiento. Esta situación genera las siguientes preguntas:

¿Cuáles son las razones éticas o antiéticas para empezar a desarrollar un negocio?

¿Es la cultura organizacional o la ausencia de ética corporativa la que determina el comportamiento en los negocios?

¿Hay a veces decisiones anti-éticas necesarias para lograr el éxito? 
Un buen ejemplo es la polémica generada por Google y sus operaciones en China. Este país bloqueo algunos sitios web porque los consideraron como un peligro para la seguridad estatal. Google no tuvo problemas sobre la restricción de información en este país y opero de acuerdo al asesoramiento del gobierno chino. Sin embargo, Google después de un tiempo decidió salir de este mercado. Esta situación deja dos preguntas: ¿Estaba Google ejerciendo sus valores éticos en China? y ¿Cuáles fueron las reales razones para dejar el país Asiático?

Uno de los principios de Google es respetar la protección de la libertad de expresión de sus usuarios. Esto es a favor de las libertades de los medios de comunicación (Matten, 2010).

Los principios de los derechos humanos son universales. Sin embargo, Google no fue creado para promover los derechos humanos sino para generar rentabilidad por eso opero en China desde 2006, Google sabe que este país es un gran mercado potencial que puede generar grandes ganancias como para ignorarlo.

Durante el tiempo que Google operó en China, enfrentó algunos problemas, primero no fue líder de buscadores en el mercado y compartió el declive del mercado chino. Adicionalmente, esta empresa tuvo problema con el ataque de los hackers, sufriendo robo de propiedad intelectual (Elizabeth M. Lynch, 2010). No obstante, Google, pudo haber ganado \$6 millones de dólares en el 2010.

Lynch E (2010) señaló "no hay que actuar de mala manera a menos que esto no corresponde al interés de los socios".

Google dice "no actuar de mala manera" es la base de la corporación. "No servir al mal" es la base de sus valores corporativos, sin embargo el ex Google CEO Eric Schmidt (2001 al 2011) refiriéndose al mercado chino dijo "nosotros en realidad servimos al mal pero decidimos no servir totalmente y esto fue un peor mal " (Manjoo, 2010)

Esta investigación índica que Google primero contempló los intereses de los accionistas y sus decisiones fueron basadas en una regla enmarcada por el valor del dinero más que por los derechos humanos, sin tomar en cuenta que en China se censura la libertad de expresión y que se restringe la libertad y acceso de la información de sus habitantes.

Es claro que China es una potencia y un enorme mercado, y a pesar de ello, es prácticamente imposible que el país asiático use los servicios de Google, por lo cual nace la siguiente pregunta

\section{¿Volvería o podrá Google volver a China?}

Sin duda, las compañías "nacidas mundiales" deberían ser conscientes de tomar decisiones que involucre las consecuencias globales. Estas organizaciones tienen alta tecnología, pero ¿tienen alta ética y principios morales? Es imposible negar el hecho de que una organización primero necesita hacer dinero para sobrevivir y lograr el éxito, pero ¿podría una organización dar bienestar a una sociedad si ésta quiebra?

\section{Conclusión}

La globalización es la creciente interdependencia de los países que envuelve proveedores, compradores, consumidores y gobiernos de diferentes partes del mundo (Knight, 2000).

Las empresas tradicionales primero se desarrollan en su país de origen y luego empiezan su internacionalización. Generalmente su expansión abarca 5 pasos de internacionalización.

Las organizaciones "nacidas globales" tienen la capacidad única de acceder al mercado global instantáneamente y lograr éxito pues nacen para ser internacionales. Estas empresas responden a la globalización entendiendo el nuevo ambiente de negocios que se vive hoy en día, por lo que son altamente competitivas frente a las tradicionales empresas ya establecidas. 
Las empresas "nacidas globales" toman la oportunidad que el mercado les ofrece inmediatamente. Sus estrategias están basadas en una continua innovación de sus productos y mejora de sus recursos. En consecuencia, estas empresas pueden mantener o incrementar sus ventajas competitivas constantemente porque tienen una visión global y están siempre abiertos a negociar y a entender a las diferentes culturas.

La investigación determinó que existen cuatro tipos de empresas internacionales que son el engranaje de la economía de muchos países que tienen diferencias entre ellas pero también similitudes.

Este documento de revisión, encontró que si las empresas desean mantener su objetivo de crecimiento y aumento de riqueza, deben tener una estrategia clara y conocer porque han sido exitosas, para ello deben hacer algunos análisis con el FODA, PESTEL y las Cinco Fuerzas de Porter, para entender no solo su industria y entorno, sino también, sus fortalezas y debilidades para no solo sobrevivir en el mercado, sino para ser los líderes de su industria.

Las empresas que nacieron globales encuentran su éxito ya que alcanzan los nichos de mercado con una innovación constante de productos y/o servicios. Que en un promedio de dos años ya empezaron a exportar a pesar de que sus operaciones no son graduales y posean una escasez de flujo de caja.

Las empresas que "nacieron globales" al igual que todas las empresas necesitan cumplir las necesidades y objetivos de sus accionistas, pero nunca deberían dejar de lado su responsabilidad social y los buenos valores éticos. La responsabilidad social marca el paso del bienestar de la sociedad, de los habitantes de este mundo globalizado.

Las organizaciones deben entender que no operan en un mundo aislado, que el retribuir a su entorno, respetar el medio ambiente y regirse con normas de valor y normas de buena conducta crearan más cercanía entre la compañía, clientes, y trabajadores generando más ganancias, sostenibilidad y prestigio.

Las organizaciones son conscientes de su responsabilidad social y esta podrá darse de una forma trasparente cuando las empresas tengan una cultura organizacional basada en el respeto, los buenos valores éticos y el respeto en el ser humano.

El resultado de haber "nacido global" significa enfrentar diferentes valores éticos, perspectivas y hábitos entre culturas, pero a la vez significa generar riqueza, trabajo y contribuir a vivir en un mundo mejor.

Sin duda las organizaciones nacidas globalizadas provocan un impacto social, que en algunos casos rompen con nuestra privacidad, poniéndonos en riesgos y obteniendo grandes ingresos a costa de nuestra vida personal.

La investigación determinó que las empresas que nacieron globales han adquirido poder y son el eje de crecimiento de muchos países, que los gobiernos han fracasado en generar riqueza para su pueblo y que por lo tanto estas empresas juegan un papel preponderante en la economía de los pueblos.

Por ello, no solo las empresas que nacieron globalizadas, deben identificarse con principios y buenos valores éticos, sino todas las actividades que envuelvan crear negocios.

Las acciones de un negocio deberían estar fundadas en los buenos valores, basado en lo que es bueno, y lo que es óptimo para todos. 
Desafortunadamente, en las actividades de los negocios hay una brecha entre hacer algo bueno y hacer lo correcto (decisiones éticas) porque hay que sobrevivir y generar prosperidad para la organización y sus accionistas. Una empresa en bancarrota no podrá generar retribución social. La investigación determinó que pueden existir diferencias éticas, pero que la integridad y la cooperación deben ser las que generen la satisfacción de alcanzar los objetivos; y no la ambición que genera el dinero. Eso es servir al "mal".

\section{Referencias bibliográficas}

(s.f.).(16 de Octubre 2017). Acerca de Amazon. Descubre nuestra empresa y nuestra tecnología Obtenido de https://www.amazon.es/Acerca-Amazon-Descubre-Nuestra-Empresa-NuestraTecnologia/b?ie=UTF8\&node $=1323175031$

Adrian Palmer, . H. (2002). The Business Environment. Chicago: McGraw-Hill.

Bakan, J. (2005). The Corporation: The Pathological Pursuit of Profit and Power. New York: Blackwell Pub.

Benjamin M. Oviatt, P. P. (2005). Defining International Entrepreneurship and Modeling the Speed of Internationalization. Atlanta: Emerald Gruop.

Brenes Leiva, G., \& León Darder, F. (2008). Las Born Global: Empresas de acelerada internacionalización. TEC Empresarial, 9-17.

Burns, P. (2001). Entrepreneurship and Small Business. London.

Elizabeth M. Lynch. (30 de Marzo de 2010). chinalawandpolicy. Obtenido de googles-profitsin-china: http://chinalawandpolicy.com/tag/googles-profits-in-china/

Friedman, M. (1970). The Social Responsibility of Business is to Increase its Profits. The New York Times Magazine, 48.

Giménez, C y Sancha, C. (2015) Estrategias de Globalización de las Multinacionales Españolas. Cuarto informe anual del OEME. Barcelona. Obtenido de: http://itemsweb.esade.es/research/oeme/informes/cuartoinforme/OEME_4\%20informe_Capitulo\%203.pdf

Hall, M. (17 de Agosto de 2017). Encyclopedia Britannica. Obtenido de https://www.britannica.com/topic/Amazoncom

Johanson, J. y Vahlne, J. (1990). The mechanism of internationalisation. International Marketing Review, 7(4):11-24.

Johnson, G. (2005). Exploring Corporate Strategy. England: Prentice Hall.

Manjoo, F. (10 de Agosto de 2010).www.slate.com. Obtenido de dont_be_evil_20:

http://www.slate.com/articles/technology/technology/2010/01/dont_be_evil_20.html

Matten, C. A. (2010). Business Ethics . Oxford: Oxford University Press.

McDougall\&Ovaitt. (2005). Toward a theory of international new ventures. Journal of International Business Studies, 12-25.

McKinsey\&Company. (1993). Emerging exporters : Australia's high value-added manufacturing exporters : final report of the study / by McKinsey \& Company and the Australian Manufacturing Council Secretariat to the Australian Manufacturing Council. Melbourne: Libraries Australia.

Mika Gabrielsson, K. a. (2004). Born globals: how to reach new business space rapidly. INTERNATIONAL BUSINESS REVIEW.

Novoa, J. (2013). Amazon, un gigante con luces y sombras. Obtenido de https://www.xataka.com/historia-tecnologica/amazon-un-gigante-con-luces-y-sombras Paul Burns, J. D. (1996). Small Business and Entrepreneurship. Southern Europ: Macmillan.

Paul W. Dobson, K. S. (2004). Strategic Management: Issues and Cases. Australia: Blackwell Publishing.

Persinger, E. C. (2007). The Born Global Entrepreneur In Emerging Economies. International Business \& Economics Research Journal. New York: Emerald Group .

Porter, M. E. (1985). Competitive Advantage: Creating and sustaining superior performance. Business \& Economics.

Rivera, C. (16 de Octubre de 2017). Historia de Toyota. Obtenido de

http://es.calameo.com/read/003466746510470ab2d13

Robbins, S. P. (2009). Comportamiento Organizacional. Mexico: Pearson Educación. 
Siropolis, N. C. (1998). Small Business Management. SIROPOLIS, 65.

Warman. (2010). https://www.global.weir/brands/warman/. Obtenido de Warman.

Wendell L. French, C. B. (1999). Organization Development: Behavioral Science Interventions for Organization Improvement. Englewood: Prentice Hall.

Welch, L., \& Luostarinen, R. (1999). Internationalization: Evolution of a Concept. En P.

Buckley, \& P. Ghauri, The internationalization of the firm (págs. 83-98). London: Thompson.

WetFeet. (2008). McKinsey \& Company. WETFEET, INC. 